\title{
O SENTIDO DO TRÁGICO NA PAISAGEM SONORA DO MUNDO URBANO CONTEMPORÂNEO ${ }^{1}$
}

\author{
Ana Luiza Carvalho da Rocha \\ Viviane Vedana \\ Priscila Farfan Barroso
}

\section{Introdução}

As sonoridades de um fim de tarde em uma grande cidade, como é o caso de Porto Alegre, no Rio Grande do Sul, com seu trânsito intenso ecoando diferentes intensidades de motores, com o som impaciente da buzina que reclama/protesta a situação das ruas engarrafadas, o alarido das crianças que deixam à escola, são apenas exemplos de como pensar uma imagem de cidade em fim de tarde.

A paisagem sonora do mundo urbano contemporâneo tem sido apontada por muitos estudiosos das condições ambientais nas grandes cidades como a responsável pelo stress, a irritação e o desgaste físico e emocional de seus habitantes, cada vez mais submetidos à pressão da artificialidade tecnológica do seu ambiente psicosocial. Neste sentido é que as sonoridades da vida urbana advindas das profundas mudanças culturais das sociedades ocidentais, marcadas pelo rápido crescimento urbano e industrial, a movimentação demográfica e as novas tecnologias podem ser enfocadas como parte dos estudos sobre o fenômeno da tragédia da cultura apontado por G. Simmel, em fins do século XIX. Se os sons da rua antes se caracterizavam pelos "moedores de melodias" (Tinhorão, 2005), do realejo, dos afiadores de faca, dos vendedores de picolé, dos pregões dos mercados públicos, dos apitos das fabricas, dos sinos das igrejas, as serenatas e as bandas militares, latidos de cachorros, hoje, junta-se a alguns deles uma paisagem sonora outra, a dos "ruídos" como a dos telefones celulares, das buzinas e de travadas de pneus de carros, de tiros e de gritos, de motores de ônibus, ruídos de betoneiras, buzinas de ambulância e carros de policia, das músicas dos bares e casas de shows, dos aviões e helicópteros, dos estádios de futebol, etc.

Os sons que compõem a vida humana veiculam as práticas sociais que os conformam e na composição da vida urbana, não se trata mais de um concerto da natureza (Schafer, 2001:212), pois revela os encontros fortuitos na rua, os rituais cotidianos de compras de alimentos para a casa, os itinerários dos habitantes que percorrem as ruas da casa para o trabalho e vice-versa, as expressões religiosas de diversos tipos, a sociabilidade dos bares e das calçadas, a vida cotidiana no bairro, entre muitos outros, e são aspectos que podem ser

\footnotetext{
1 “Trabalho apresentado na $26^{\mathrm{a}}$. Reunião Brasileira de Antropologia, realizada entre os dias 01 e 04 de junho, Porto Seguro, Bahia, Brasil.”;
} 
etnografados para se pensar as feições que a crise assume no contexto das modernas sociedades complexas. A composição de vozes e trânsito, dos sons de passos e risadas, das sonoridades dos utensílios técnicos: celulares, caixas-registradoras, o barulho do arcondicionado, televisão, rádio, etc. remetem à complexidade do ambiente urbano em termos de suas expressões sonoras.

Para Schafer (2001), o mundo urbano contemporâneo está sonoramente poluído, e uma das razões seria o aumento irreversível das obras da cultura que produzem máquinas e tecnologias, responsáveis pela produção de ruídos não-informativos - em relação às antigas sonoridades (assobio, sino) - que por sua vez habitam o mundo dos mais diversos sons. Para Schafer, uma degradação da paisagem sonora mundial, o que o levou a elaborar um projeto de despoluir sonoramente o mundo. Para o autor, se podemos fechar os olhos em situações em que estamos vulneráveis e expostos, os ouvidos, pelo contrário, permanecem abertos a mercê do horizonte acústico em que se vive. Estes comentários do autor (Schafer, 2001:680) nos permitem pensar, portanto, o tema do ruído (som indesejável) na paisagem sonora das grandes metrópoles como parte do que G. Simmel denominou, a tragédia da cultura.

A polêmica que reúne o ruído (todo e qualquer som que interfere) ao seu oposto, o silêncio (ausência de som pelo fato de que um determinado evento sonoro é colocado no interior de um recipiente), como parte do ambiente acústico das cidades modernas, seguindose G. Simmel (1932:13), é uma pista interessante de investigação sobre a síntese singular entre a cultura subjetiva e a cultura objetiva (os tesouros culturais de uma época) que configuram as formas de vida social nos grandes centros urbano-industriais e seus territórios. Sob este ângulo, na metrópole contemporânea as formas adotadas no jogo entre o ruído e o silêncio, este último como caixa de possibilidades (Schafer, 2001:71), revelam-se, portanto, como uma das formas expressivas (Dawsey, 2000) do social através das quais se pode desvendar os modos de ser e de estar no mundo de seus habitantes.

Segundo Simmel (1932:177), o homem não se coloca ingenuamente no mundo, como o animal, ao contrário, ele se destaca, se enfrenta com ele, o provoca e luta, o vence ou é por ele vencido. Neste sentido, podemos retomar algumas afirmações de Schafer (2001:71) sobre silêncio e ruído para se re-situar o tema da tragédia da cultura nas metrópoles contemporâneas. Ou seja, a controvérsia entre silêncio e ruído: se o silêncio (escuridão auditiva) revela a presença da subjetividade humana na produção de uma cultura objetiva (por exemplo, um evento musical), o ruído (som que interfere) que se origina na dimensão objetiva da cultura humana, manifesta a presença da vida subjetiva no mundo (a ausência de som evoca a ausência de vida). Nos termos colocados por Eckert e Rocha (2005), o desafio é se pensar as representações de desordem externa - caos, poluição, desordem e violência - às 
próprias representações de desordens internas no trajeto da emergência do individualismo moderno.

Portanto, diferentemente de Schafer (2001), não pensamos as grandes metrópoles contemporâneas desde a forma fixa de uma oposição entre os sons da natureza e os sons da cidade, e tampouco abordamos os temas da poluição sonora e dos ruídos referidos às feições de crise e da desordem de uma paisagem sonora urbana degradada. Ao contrário, relendo-o desde a perspectiva simmeliana, podemos afirmar que toda a cultura humana nasceria, portanto, da concorrência de elementos de silêncio, sons e ruídos, e interessa-nos compreender, através das sonoridades, as formas que compõem a vida urbana e os sentidos elas que evocam ao longo do tempo na configuração de cidade. Sob ótica da etnografia da duração, de inspiração bachelardiana (Bachelard, 1988) sabemos que as formas que adotam os sons nas grandes cidades moderno-contemporâneas não são realidades fixas, mas se transfiguram umas em outras, e assim, o tema da poluição sonora e do ruído pode ser enfocado então como parte da crise da vida nas grandes metrópoles na medida em que se atribui as suas sonoridades um sentido cultural associado aos processos de formação da consciência subjetiva moderna e aos seus conteúdos.

O estudo das sonoridades urbanas, para além de seus conteúdos objetivamente normatizados e ordenados, podem nos auxiliar na compreensão da cultura subjetiva moderna que acompanha a transformação da vida social nas grandes metrópoles e as descontinuidades das práticas cotidianas e das sociabilidades, entendidas aqui como arranjos e re-arranjos constantes nas maneiras de viver na cidade, e onde a dimensão de um sentido do trágico no que concerne a paisagem sonora está presente em nossas preocupações etnográficas. No caso deste paper, gostaríamos de compartilhar algumas de nossas hipóteses e trajetos de investigação sobre o tema, tendo em vista algumas experiências etnográficas que vivemos nos últimos anos. Precisamente, trataremos brevemente de três pesquisas que nos revelam possibilidades de investigação a respeito da temática da crise e do conflito no que tange a questão da paisagem sonora, suas transformações e durações no tempo.

\section{Acomodação do tempo no espaço na escuta do cotidiano e do Outro}

Falamos bastante acima sobre os sons da rua, da ambiência sonora do espaço público e das formas de sociabilidade. Compõem também este cenário, os relatos dos habitantes da cidade sobre seus itinerários e suas memórias dos lugares. Suas vozes ecoam na construção da lembrança de um tempo que passou, remontando as transformações urbanas, as mudanças que deram a cidade uma nova cara. No interior da pesquisa do Banco de Imagens e Efeitos Visuais, pensar a cidade no tempo é também se interrogar sobre as imagens da memória de 
seus habitantes, de suas lembranças sobre suas experiências urbanas, e as modificações que acompanharam ao longo de sua vida. É através de suas narrativas que podemos compartilhar diferentes paisagens urbanas de uma mesma cidade, na tecitura da lembrança da voz que conta sua história.

Dessa forma é que pudemos conhecer a cidade de Porto Alegre sob o ponto de vista (e porque não dizer de escuta?) de alguns religiosos de matriz africana ${ }^{2}$, mais precisamente do Batuque do Rio Grande do Sul, que explicitaram em suas entrevistas suas dificuldades e possibilidades de fazer durar esta religião e seus rituais no interior de uma cidade que se moderniza. Trata-se de uma experiência etnográfica ocorrida no ano de 2007, para a realização do documentário "Os caminhos invisíveis do negro em Porto Alegre: a tradição do Bará do Mercado". Neste processo, foram entrevistados sete religiosos do Batuque de Porto Alegre sobre o assentamento de orixá existente no Mercado Público de Porto Alegre (o Bará do Mercado) e a partir disso também sobre suas memórias na cidade. Esta pesquisa etnográfica abriu possibilidades de reflexão sobre o conflito e as formas de interação e sociação (Simmel, 1981) que ocorrem em territórios urbanos e como poderíamos enfocar este tema do ponto de vista de uma etnografia sonora.

Sem entrar em detalhes mais precisos e conceituais sobre as religiões de matriz africana no Brasil e também no Rio Grande do $\mathrm{Sul}^{3}$, o que gostaríamos de apontar aqui são justamente as pistas que nos remetem a pensar na cidade e os processos que poderíamos chamar de "controle das sociabilidades", ou seja, dos sistemas de regras e disposições que estabelecem o que se pode fazer ou não por parte do poder público. Trata-se de compreender, ou melhor, de pensar junto com as falas dos religiosos sobre como são reguladas as formas de viver na cidade e como as sonoridades das formas de sociabilidade intervêm nestes processos.

Para o caso deste texto, vamos pontuar alguns aspectos relacionados à religião de matriz africana, contextualizando-a no interior da vida urbana, sem pretensão de dar conta de toda a complexidade que envolve tais sistemas de crenças, com seus rituais, suas práticas sociais e suas formas de construção de subjetividade. Um dos aspectos que nos interessa sobremaneira para o caso da discussão aqui proposta refere-se principalmente às festividades e às formas expressivas (Dawsey, 2000) que esta religião assume. O próprio nome Batuque

\footnotetext{
${ }^{2}$ O Documentário "Caminhos Invisíveis do Negro em Porto Alegre: a Tradição do Bará do Mercado" teve como equipe de produção pesquisadores do Banco de Imagens e Efeitos Visuais, e foi dirigido por Ana Luiza Carvalho da Rocha. O vídeo é parte de um projeto de divulgação e promoção do Patrimônio Imaterial da Cultura Brasileira e contou com o financiamento do Programa Petrobrás Cultural.

${ }^{3}$ Entre estes trabalhos podemos citar: Polvora, Jacqueline. A Sagração do Cotidiano: estudo de sociabilidade em um grupo de Batuqueiros em Porto Alegre/RS, dissertação de mestrado, orientador: Ari Pedro Oro, PPGAS/ UFRGS, 1994. Silva, Vagner Gonçalves da. O antropólogo e sua magia: trabalho de campo e texto etnográfico nas pesquisas antropológicas sobre as religiões afro-brasileiras, São Paulo, Edusp, 2000.
} 
origina-se do toque do tambor realizado nas festas de religião para evocar os Orixás. O tambor é, portanto sagrado, é o instrumento capaz de estabelecer o vínculo entre o mundo dos homens e o das "entidades divinas". Para que este vínculo seja estabelecido, ou seja, para que os Orixás "desçam ao mundo dos homens", o tambor precisa retumbar. O gesto rítmico da mão do tamboreiro que bate no "couro animal" com que é confeccionado o tambor provoca sons singulares, fortes, que ecoam para além do terreiro, chegando ao mundo dos Orixás, evocando-os. Acompanhando o tambor e suas batidas que atingem os corpos de quem participa do ritual, estão os cantos, os pontos de batuque reunidos nas vozes dos tamboreiros, dos pais e mães de santo, dos filhos de santo, dos adeptos da religião que dançam para seus Orixás. A energia das ondas sonoras que se propagam em uma festa como esta é quase visível a olho nu, é possível senti-las no corpo, que vibra junto.

Para os adeptos desta religião, esta ambiência de fruição estética (Maffesoli, 1996) é de extrema importância, é ela que movimenta as energias necessárias para o encontro com os Orixás. Esta ambiência corresponde a uma ética da estética (Maffesoli, 1996) da própria religião para este encontro com os Orixás, pois se trata de uma celebração. Uma celebração que poderíamos aproximar de uma missa, por exemplo, que também evoca seus cânticos, suas rezas e suas formas de ligação com a divindade. No entanto, uma diferença crucial atravessa estas formas expressivas das religiosidades: a própria construção do espaço. Enquanto a Igreja Católica edifica catedrais, capelas, etc, suntuosas obras da cultura humana, com seus vitrais, com sua decoração de santos, e com a acústica peculiar de tal ambiente, onde os sons rebatem nas paredes e giram dentro de um mesmo local, os terreiros de Batuque tem por princípio a própria terra onde são assentados seus Orixás, o chão é essencial como também o ar que propaga suas sonoridades, levando-as até suas divindades. Vendo a questão por um outro aspecto, o catolicismo é uma religião legítima dentro do processo civilizatório ocidental e branco que constitui as próprias cidades moderno-contemporâneas. Nos termos de Durand (2001), são as imagens veiculadas por esta igreja que sobredeterminam o imaginário ocidental e orientam as representações sobre a cidade e seus sistemas de crenças, seus dispositivos regulatórios sobre as formas de expressividade destes sistemas de crença.

Neste caso, como compartilhar os sentidos evocados em alto e bom som das festas de Batuque com uma população urbana que muitas vezes “demoniza” estas práticas e rituais? Na narrativa dos Babalorixás e Ialorixás que foram entrevistados para a produção do documentário "A Tradição do Bará do Mercado", a repressão a suas práticas religiosas aparece entre outros aspectos através do controle das sonoridades que afetam as vizinhanças dos terreiros. Repressão promovida não apenas pela própria polícia, mas por uma população urbana cujas crenças religiosas são "mais legítimas" do que os cultos afro, como por exemplo, 
a religião católica e atualmente também as religiões pentecostais. Durante muito tempo, com a perseguição aos cultos religiosos de matriz africana, estes grupos tenderam a se esconder, promovendo seus rituais à noite, ou em espaços menos habitados da cidade, lugares onde ainda podiam contar com "os elementos da natureza" importantes para a realização de seus rituais, como as proximidades com a água e com o mato, por exemplo.

Mas a cidade cresce, se transforma, e os espaços antes desabitados tornam-se lugares de novas moradias, muitas vezes bairros residenciais destinados as classes média e alta. Como conseqüência, os grupos religiosos e seus terreiros sofrem o impacto desta mudança com o acirramento das proibições e do rechaço as suas sonoridades. Esta situação ainda se agrava se levarmos em conta que os terreiros possuem seus "assentamentos" de orixás, ou seja, são territórios sagrados, pois um assentamento não pode ser transferido de lugar. Estamos então diante de conflitos e negociações que permeiam o cotidiano dos adeptos do Batuque e que atravessam a vida urbana de Porto Alegre ao longo dos anos. De um lado temos a expressão cultural de um grupo que tem no toque do tambor um dos elementos principais de sua religião e de outro, grupos urbanos que não compartilham destes mesmos sentidos. É claro que não podemos essencializar na sonoridade desta religião todo um conjunto de preconceitos que são experenciados até hoje por adeptos do Batuque. Esta religião e seus seguidores sofrem ainda com as representações de outras religiões que tendem a criar representações demoníacas para as práticas sociais relacionadas ao Batuque. Representações que na maior parte das vezes partem desta estética das formas: o gingado do corpo - na dança e no transe - o toque retumbante do tambor que ecoa pelos cantos e ruas, as vozes que repetem o ponto, o chamado aos Orixás, e é claro, também as sonoridades que emanam da sacralização dos animais, um dos aspectos mais fortes desta demonização.

Seguindo as contribuições de Simmel para a compreensão da vida social, apresentamos estas pistas para pensar sobre os processos de negociação e de conflito que permeiam o cotidiano urbano. Através das entrevistas que citamos aqui, nos foi possível pensar sobre as disputas de uso do espaço público no que tange as formas de sociabilidade. Escutar estas entrevistas, imaginar trajetos, reelaborar espaços vividos, experenciar as festas de Batuque, compuseram uma importante etnografia sonora da cidade de Porto Alegre. Uma etnografia que apontou para os arranjos sociais que se desdobram das negociações e conflitos entre, neste caso, os praticantes da religião do Batuque e sua vizinhança bem como com as instâncias regulatórias dos espaços urbanos.

\section{Os mercados de rua e suas formas expressivas sonoras}

Outra pesquisa etnográfica a que nos reportamos aqui para pensar as sonoridades na 
vida urbana e suas pontencialidades de re(a)presentar o tema da crise e do conflito foi desenvolvida em mercados de rua e feiras-livres de Porto Alegre e outras cidades do Brasil, gerando uma dissertação de mestrado, uma tese de doutorado, dois documentários etnográficos sonoros e diversos outros produtos ${ }^{4}$. O que vamos pontuar aqui se refere a um fragmento desta pesquisa etnográfica, que tem vínculo com a idéia de controle das sociabilidades de que falamos acima.

Em primeiro lugar é importante apresentar o universo de pesquisa: Mercadão do Produtor, que ocorre todos os sábados pela manhã, no Largo Zumbi dos Palamares, bairro Cidade Baixa, em Porto Alegre. Um bairro eminentemente residencial, mas com grande comércio de pequeno porte, como armazéns e bares noturnos. Muitos estudantes habitam este bairro, além de famílias de classe média. Há aproximadamente 25 anos atrás esta feira-livre passou a ocorrer neste local, em decorrência de algumas reformas urbanas que modificaram as feições desta região. A partir do ano de 2006, o estabelecimento desta feira-livre no Largo Zumbi passou a ser ameaçado pela criação dos Portais da Cidade, um projeto que prevê a construção de terminais de ônibus em algumas regiões da cidade de Porto Alegre. Com a criação deste portal no Largo Zumbi dos Palmares, a feira seria deslocada de lugar e com isso, certamente desestruturadas as redes de sociabilidade e solidariedade que existem no interior deste mercado de rua.

Este fato no remete a pensar no lugar destes mercados de rua no interior da cidade, nas adesões e recusas a esta ambiência de fruição estética (Maffesoli, 1996) bem como nas representações sobre a cidade veiculadas na mídia ou pela Prefeitura Municipal, como é possível acessar através do vídeo pwvideo1.procempa. com.br:8080/ Portaisdacidade, por exemplo, veiculado pelo site da Prefeitura Municipal de Porto Alegre. Neste vídeo, evidenciase que regiões como o Centro da cidade, diariamente ocupados por milhares de habitantes em seus afazeres cotidianos, repleto de comércios populares, são encaradas como caóticas e problemáticas, violentas, poluídas, que necessitam de regulação e controle. Na próxima parte deste texto trataremos mais especificamente sobre o Centro de Porto Alegre, aqui cabe considerar como estas representações atingem o mercado de rua do Largo Zumbi dos Palmares e projetam uma transformação deste espaço da cidade.

A composição de um mercado de rua nas praças e largos de uma cidade não é um evento que passe despercebido. Para o caso do Mercadão do Produtor, no Largo Zumbi, ainda durante a madrugada, feirantes vindos do interior do estado do Rio Grande do Sul ou mesmo

\footnotetext{
${ }^{4}$ Ver, por exemplo, VEDANA, Viviane. No Mercado tem tudo que a boca come. Estudo Antropológico da duração das práticas de mercado de rua no mundo urbano contemporâneo. Tese de Doutorado defendida no Programa de Pós-Graduação em Antropologia Social/UFRGS, Orientador: Cornelia Eckert, 2008.
} 
de bairro mais periféricos de Porto Alegre chegam para montar suas bancas. Uma movimentação ruidosa no silêncio das cinco horas da manhã. Tábuas de madeira que são lançadas ao chão para a montagem das bancas de hortifrutigranjeiros, caixas e caixas de alimentos que serão vendidos ao longo da manhã são deslocadas para comporem as bancas, os motores dos caminhões que chegam ao largo, são elementos que começam a compor a paisagem sonora de um dia de feira.

Mas este, diríamos, não é o elemento mais importante. A efervescência da feira é crescente em termos das sonoridades que produz. O Largo Zumbi transforma-se em dias de mercado em um espaço pleno de sonoridades que acabam por marcar o cotidiano do bairro. Com a feira-livre montada, e a confluência de pessoas que a ela se dirigem para fazer suas compras, a paisagem sonora (Schafer, 2001) do Bairro Cidade Baixa ganha outros tons. Reunidas às sonoridades cotidianas do trânsito da cidade, configuram-se as performances orais dos feirantes, em seus pregões e anúncios de produtos, nas conversas e breves diálogos, nas jocosidades que perduram durante a feira. Nas práticas cotidianas dos fregueses, incluemse o percurso com carrinhos de feira pelas calçadas do bairro, as conversas de esquina, o diálogo e os micro-eventos (Moles, Rohmer, 1982). O mercado de rua configura-se como um arranjo social que se desdobra dos simbolismos da circulação do alimento presentes na vida urbana, e desta forma possibilita a circulação de imagens que carregam esta potência simbólica, produzindo um espaço vivido particular no interior das ruas de uma cidade.

A combinação das sonoridades do mercado, como camadas distintas de composição de uma estética particular dada na experiência de estar-junto-com (Maffesoli, 1996) apresentamse como possibilidades interpretativas sobre uma determinada paisagem urbana, não apenas vinculada aos sofrimentos de uma poluição sonora, relacionando a cidade a uma imagem de caos sonoro, mas estetizada a partir de uma escuta dos gestos ordinários, compondo e evocando sentidos diversos para o viver na cidade. No entanto, é justamente aí que nos deparamos com as situações de conflito e crise. Esta ambiência de fruição estética do Mercadão do Produtor "não combina" com a estética dos arranha-céus e hotéis luxuosos que vem sendo construídos na Perimetral Loureiro da Silva, onde se situa o Largo Zumbi. A idéia de criação de um Portal de Ônibus moderno, seguro, e silencioso converge com as edificações que têm sido construídas nos últimos anos no bairro Cidade Baixa.

Este projeto está longe de ser consenso entre moradores do bairro e habitués do mercado, que já organizaram discussões, abaixo-assinados e outras formas de reivindicar a não instalação deste terminal de ônibus. O movimento negro, que também tem no Largo Zumbi um importante local de celebração cultural e política, reivindica a não instalação deste portal, no entanto, as tratativas da prefeitura para a execução deste projeto continuam, como 
que alheias a estas reivindicações. O impacto desta instalação no Bairro tem sido a preocupação principal de seus moradores, principalmente no que se refere à mudança de suas feições. O processo de disciplinamento do espaço e das formas de uso do mesmo nos parece evidente, na medida em que o Portal, um lugar fechado com aparência de shopping-center, contará com estabelecimentos comerciais diversos, praça de alimentação, além do terminal de ônibus, tudo previamente calculado para o bem-estar do cliente, garantindo sua segurança e individualidade, como consta nas discursividades do poder público. Mais uma vez, um quadro de controle das formas e usos do espaço, das formas de sociabilidade se apresenta a pesquisa sobre a vida urbana no interior do Banco de Imagens e Efeitos Visuais.

\section{Cacofonias urbanas: o centro de Porto Alegre e o comércio popular}

O terceiro estudo que apresentamos aqui se refere a uma pesquisa etnográfica que vem sendo realizada na Rua Voluntários da Pátria, em Porto Alegre ${ }^{5}$ Nesta pesquisa, os procedimentos de uma etnografia de rua (Eckert, Rocha, 2001) combinados com uma etnografia sonora (Rocha, Vedana, 2007) apontam para situações de crise e conflito vividas no cotidiano do centro da cidade no que diz respeito às formas de ocupação deste espaço.

Nesta rua do centro de Porto Alegre vendedores ambulantes de CD's e DVD's faziam o comércio de seus produtos, anunciando-os a alto e bom som, para atrair fregueses. A complexidade da ambiência sonora desta rua compõe-se também pelo trânsito ruidoso dos ônibus que por ali passam, dos anúncios de lojistas que aderem à calçada para oferecer suas mercadorias aos passantes, e é claro também pelas sonoridades efêmeras de quem transita pela rua, das conversas, risadas, telefones que tocam, etc.

Mas esta paisagem sonora se transformou radicalmente ao final do ano de 2007, com o início da construção de um Centro Popular de Compras para abrigar camelôs (situados na Praça XV, há alguns metros da Rua Voluntário da Pátria) e a repressão da Secretaria Municipal de Indústria e Comércio de Porto Alegre em relação ao comércio de CD’s e DVD’s na região. A memória coletiva da cidade de Porto Alegre compartilha uma imagem da Rua Voluntários da Pátria como espaço destes diversos comércios, uma rua popular, com as pessoas ocupando a rua e a calçada para as mais diferentes práticas sociais, como podemos ver atualmente trabalhadores se alimentando sentados em um banco, na própria rua, com a marmita que trouxeram de casa ou com o lanche que compraram de algum vendedor ambulante. No interior destas sociabilidades populares inseriam-se também os vendedores

\footnotetext{
${ }^{5}$ Ver artigo de Priscila Farfan "Caminho por nuances sonoras de uma rua habitada: vendedores ambulantes e seus rastros perseguidos". In: Revista Chilena de Antropologia Visual, $\mathrm{n}^{\circ} 11$ (no prelo), e também etnografia sonora intitulada "Voluntários da Pátria".
} 
ambulantes de CD's e DVD's e suas práticas de venda, seus anúncios de produtos, suas maneiras de estar na rua.

No entanto, os projetos de revitalização do centro da cidade afetam estas práticas na medida em que se orientam para a construção de uma cidade higienizada destas formas populares de uso das ruas, destinada a flanerie, ao passeio, ou como bem aponta Simmel, a uma sociedade do espetáculo. Obras como este Centro Popular de Compras ou mesmo os Portais da Cidade incidem justamente sobre as sociabilidades e as interações cotidianas, sobre as práticas dos sujeitos que habitam a cidade, procurando o controle destas. Segundo Gutton (2000), o controle dos sons nos espaços públicos, está historicamente relacionado com o processo de "civilização dos costumes" (Elias, 1994) e com o disciplinamento dos espaços públicos.

\section{À Guisa de Conclusão}

As feições dos medos, dos conflitos e das crises urbanas, conforme aponta Cornelia Eckert, remetem ao crescente individualismo da sociedade moderna, e seus valores de privacidade, proteção ao patrimônio, liberdade e isolamento, entre outros. Valores que nos conduzem a pensar no receio ao estranho, ao diferente - conforme Eckert, medo do estrangeiro - que podemos perceber nas disputas pelo uso do espaço, na dificuldade de negociação com as sonoridades do Batuque, por exemplo, no meio urbano. A crise que podemos pesar aqui, relacionada a uma paisagem sonora do Batuque, está relacionada a uma forma sonora que aproxima a cultura da natureza, onde o retumbar do tambor evoca a própria sacralização dos animais para o ritual. A descontinuidade de sentidos entre adeptos e não adeptos desta religião para o caso da convivência no meio urbano produz a crise nas formas de sociabilidade e interação nos arranjos cotidianos urbanos, tendo em vista que "a cidade que vemos é a que criamos com o outro" (Eckert, 2005), se temos uma cidade em crise, ela é também parte da crise coletiva e individual de seus habitantes.

Seguindo a teoria simmeliana da forma, a crise e o conflito engendram a vida social, na medida em que propicia a negociação e conduz a diferentes arranjos. Nesta dimensão da crise insere-se a idéia de um "movimento relacional e interdependente entre o mundo subjetivo e o mundo objetivo que constitui a vida social humana" (Eckert, 2005). Objetivamente criam-se dispositivos para regular e controlar as sociabilidades e as sonoridades da vida humana, dispositivos aos quais a cultura subjetiva precisa se adequar, rearranjando-se. A vida social, portanto, é uma constante transformação das relações do homem com o mundo.

O que causa desconforto, no entanto, ao pensarmos a cidade do ponto de vista de sua 
administração pública, é que estes arranjos sociais (Rocha, 1995) e cotidianos fogem ao controle do Estado, por exemplo, na medida em que são vivido e negociados no dia-a-dia, entre as pessoas que interagem. Neste caso, tanto o mercado de rua como a Rua Voluntários da Pátria em Porto Alegre apresentam o "risco" da vida cotidiana, risco de uma sociabilidade popular pautada no riso, nas formas jocosas, no uso da rua para "práticas privadas" como a alimentação, por exemplo. A instauração de obras como os Portais da Cidade, ou mesmo o Centro Popular de Compras, visam conter estas formas de expressão de uma cultura popular que a subjetividade moderna citadina atribui demasiada aproximação com a natureza, dirigindo-lhes sentimentos sombrios. Aproximamo-nos assim, da estética do grotesco (Bakhtin, 1996) tão bem descrita por Bakhtin em relação à cultura popular.

Mais uma vez, a estas sociabilidades populares e públicas são atribuídas valorizações negativas, onde o ruído aparece como efeito de poluição sonora - a cidade é caótica visual e sonoramente no que concerne a estes espaços. Ruído, sujeira, mau cheiro são as imagens relacionadas a estas formas de sociação (Simmel, 1981) onde os arranjos sociais de massa se confrontam com a idéia de privacidade nos espaços públicos. O volume e a massa são característicos das formas de sociação popular, ao contrário do ideário do individualismo moderno que propõe a contração da sociabilidade pública, sua higienização e civilização. As sonoridades das risadas altas, das jocosidades que remetem ao baixo ventre (Bakhtin, 1996), a voz que grita e anuncia/denuncia a tênue fronteira entre os sons públicos e os sons privados convocam ao estudo das formas sonoras que compõem a paisagem urbana de uma cidade e os arranjos sociais que a constituem em seu trajeto antropológico (Durand, 2001).

Inversamente, em termos das sonoridades e de uma paisagem sonora urbana, quais são os riscos - para pensarmos em termos da crise como um sentimento permanente no que concernem as mudanças urbanas - que uma obra como os Portais da Cidade trazem consigo? O trânsito intenso de ônibus nesta região da cidade, o aumento do número de transeuntes seria o preço para a revitalização do centro da cidade? Os desenraizamentos inevitáveis presente nesta intervenção urbana - bem como no caso da construção do Centro Popular de Compras e a retirada dos camelos da Praça XV - ou seja, o impacto ambiental - em termos das pessoas inseridas em seus contextos cotidianos - destas obras são de grande monta, a se ver já pelo "silêncio das sociabilidades" (Farfan, 2008) vivido na Rua Voluntários da Pátria.

Novamente pensando com Simmel, os sons e as formas expressivas da cultura no permitem o devaneio (Bachelard, 1988) sobre o que virá. A paisagem sonora urbana está em constante crise, no sentido das transformações que tem lugar na cidade. Com as questões que apresentamos neste texto, apontamos justamente algumas formas de pensar esta crise, a partir de etnografias sonoras urbanas. 


\section{Referências Bibliográficas}

BACHELARD, Gaston. A Dialética da Duração. São Paulo, Editora Ática, 1988.

BACHELARD, Gaston. A Poética do Espaço. São Paulo, Editora Ática, 2000.

BAKHTIN, Mikhail. A Cultura Popular na Idade Média e No Renascimento: o contexto de François Rabelais. São Paulo-Brasília, HUCITEC-EDUNB, 1996.

CERTEAU, Michel de. A Invenção do Cotidiano. Vol 1. Rio de Janeiro, Vozes, 1994.

CHION, Michel. Le son.Paris, Armand Colin, 2004.

DAWSEY, John Cowart. Nossa Senhora Aparecida e a Mulher Lobisomem : Benjamin, Brecht e o teatro dramático na Antropologia. In: Ilha, Revista de Antropologia. Florianópolis, Vol. 2, no 1, dezembro de 2000.

DURAND, Gilbert. As Estruturas Antropológicas do Imaginário. São Paulo, Martins Fontes, 2001.

ECKERT, Cornelia A cidade e seus medos. Iluminuras: Série do Banco de Imagens e Efeitos Visuais, número 4. Porto Alegre: BIEV, PPGAS/UFRGS, 2000

ECKERT, Cornelia e ROCHA, Ana Luiza C. da. Imagens do tempo nos meandros da memória: por uma etnografia da duração. Iluminuras: Série do Banco de Imagens e Efeitos Visuais, número 4. Porto Alegre: BIEV, PPGAS/UFRGS, 2000.

ECKERT, Cornelia e ROCHA, Ana Luiza C. da. Etnografia de rua: estudo de antropologia urbana. Iluminuras: Série do Banco de Imagens e Efeitos Visuais, número 44. Porto Alegre: BIEV, PPGAS/UFRGS, 2001.

ECKERT, Cornelia e ROCHA, Ana Luiza Carvalho da. "O porto pouco seguro: estudo da cultura do medo em Porto Alegre". In: Iluminuras, Série do Banco de Imagens e Efeitos Visuais, número 80. Porto Alegre: BIEV, PPGAS/UFRGS, 2005.

ECKERT, Cornelia e ROCHA, Ana Luiza C. da. O Tempo e a Cidade. Porto Alegre: Editora da UFRGS, 2005.

ELIAS, Norbert. O Processo Civilizador II. Uma história dos costumes. Rio de Janeiro, Jorge Zahar Editores, 1994.

FARFAN, Priscila "Caminho por nuances sonoras de uma rua habitada: vendedores ambulantes e seus rastros perseguidos". In: Revista Chilena de Antropologia Visual, $\mathrm{n}^{\mathrm{o}} 11$ (no prelo).

GUTTON, Jean-Pierre. Bruits et sons dans notre histoire: essai sur la reconstituition du paysage sonore. Paris, PUF, 2000.

MAFFESOLI, Michel. No Fundo das Aparências. Petrópolis, RJ, Vozes, 1996.

MAUSS, Marcel. Sociologia e Antropologia. São Paulo, Cosac \& Naify, 2003.

MOLES, H. et ROHMER, E. Labyrinthes du Vécu. Paris, Librairie des Meridiens, 1982.

TINHORÃO, José Ramos Os sons que vem da rua. São Paulo, ed. 34, 2005.

ROCHA, Ana Luiza Carvalho da. A irracionalidade do belo e a estética urbana no Brasil. In MESQUITA, Z. e BRANDÃO, C. R. Territórios do cotidiano: uma introdução a novos olhares e experiencias. Porto Alegre/Santa Cruz do Sul, UFRGS/UNISC, 1995.

ROCHA, Ana Luiza Carvalho da. VEDANA, Viviane. A representação imaginal, os dados sensiveis e os jogos da memória: os desafios do campo de uma etnografia sonora. In: Anais do VII Congresso de Antropologia do Mercosul (VII-RAM), Porto Alegre, 2007, CD-ROOM. SANSOT, Pierre. Les Formes Sensibles de la Vie Sociale. Paris, PUF, 1986.

SCHAFER, Murray. A Afinação do Mundo. São Paulo, Editora Unesp, 2001.

SIMMEL, Georg. A Metrópole e a Vida Mental. In VELHO, O. (org.) O Fenômeno Urbano.

Rio de Janeiro, Zahar, 1979.

SIMMEL, Georg. Sociologie et Epistémologie. Presses Universitaires de France, 1981.

SIMMEL, Georg. Les problèmes de la philosophie de l'Histoire. Paris, PUF, 1984

SIMMEL Georg. Cultura femenina y otros ensayos, Revista de Occidente, Madrid, 1932. 
VEDANA, Viviane. Fazer a Feira: estudo etnográfico das "artes de fazer" de feirantes e fregueses da Feira-Livre da Epatur no contexto da paisagem urbana de Porto Alegre. Dissertação de Mestrado defendida no Programa de Pós-Graduação em Antropologia Social da UFRGS sob Orientação da Professora Doutora Cornelia Eckert, 2004.

VEDANA, Viviane. Sonoridades da Duração: práticas cotidianas de mercado no mundo urbano contemporâneo. Uma introdução à construção de coleções etnográficas a partir dos dados imagéticos de campo. In: Anais do VII Congresso de Antropologia do Mercosul (VIIRAM), Porto Alegre, 2007, CD-ROOM.

WISNIK, José Miguel. O Som e o Sentido. São Paulo, Companhia das Letras, 1989.

\section{Sites consultados}

Prefeitura Municipal de Porto Alegre

http://www2.portoalegre.rs.gov.br/ 